\title{
Chronic middle foot pain in a patient with a swollen leg: diagnosis and discussion
}

\author{
Grzegorz Marek Karwacki • Ueli Studler • \\ Tilo Niemann
}

Received: 10 May 2011 / Revised: 29 June 2011 / Accepted: 4 July 2011 / Published online: 9 August 2011

(C) ISS 2011

\begin{abstract}
Answer
Diagnosis

Insufficiency fracture of fourth metatarsal bone in a patient with Klippel-Trénaunay syndrome.
\end{abstract}

\section{Discussion}

Klippel-Trénaunay-Weber or simply Klippel-Trénaunay syndrome (KTS) also known as osteoangiohypertrophy syndrome or nevus vasculosus hypertrophicus is a rare congenital non-inheritable venous disorder of unknown origin. A classical symptom triad of port-wine stain, varicosis, and limb hypertrophy was first described by the two French physicians Maurice Klippel and Paul Trénaunay in 1900 [1].

The etiology of KTS is still not determined. Klippel and Trénaunay speculated that a spinal cord abnormality might be the cause of observed symptoms. Other authors believe that atresia of the deep leg veins or developmental mesodermal defect could be the underlying cause [2]. Current findings suggest that KTS is a result of mutation of an angiogenic factor gene [3].

The case presentation can be found at doi:10.1007/s00256-011-1237-9.

G. M. Karwacki $(\bowtie) \cdot$ U. Studler $\cdot$ T. Niemann

Department of Radiology, University Hospital Basel,

Petersgraben 4,

4031, Basel, Switzerland

e-mail: karwackig@uhbs.ch

U. Studler

e-mail: studleru@uhbs.ch

T. Niemann

e-mail: niemannt@uhbs.ch
Diagnosis is usually based on the presence of at least two classic symptoms at birth or in early childhood.

Cutaneous manifestations are red to purplish in color and can be found on any part of the body in $98 \%$ of patients [4]. They are vascular malformation-ectatic, thin-walled capillaries in the dermis.

Varicosis is found in $72 \%$ of the KTS-affected population [4]. The deep venous system of an affected limb might also be involved. Of high importance are visceral vascular malformations as they can cause severe hemorrhages. Lymphatic system involvement in the form of malformations is reported in $11 \%$ of patients [4].

Jacob et al. found that $67 \%$ of KTS patients present with a limb hypertrophy limited to one leg but more limbs and head or trunk might also be involved [4]. In an overwhelming majority of cases, girth and/or length of involved extremity is increased, but decrease of length and width have also been reported [5]. The limb enlargement develops because of soft tissue hypertrophy with or without bone hypertrophy. Associated findings include macrodactyly, syndactyly, and polydactyly [6]. Affected bones are elongated and show cortical thickening. An imaging feature of advanced stages is osteoporotic-like changes owing to intraosseous vascular malformations as seen in our patient [7].

In many patients there is no treatment needed, although compression stockings are recommended for all of them [8]. Skin care is advised to avoid cellulitis. In mature patients with leg length difference of more then $2 \mathrm{~cm}$, surgical shortening of the affected limb might be considered. Superficial as well as deep vascular malformations might be treated by laser therapy, excision, cryotherapy, sclerosis, and ligation.

In the presented patient, osteoangiohypertrophy syndrome of left leg has been diagnosed in childhood. Because of chronic foot pain, a radiograph was performed that showed phleboliths, osteopenia of the first to third metatarsal and 
callus at the diaphysis of fourth metatarsal (Fig. 1). After 2 weeks, a work-up MRI was performed and showed softtissue hypertrophy, varicosis, phleboliths, and a fracture of the fourth metatarsal bone with callus (Fig. 2). There was no bone hypertrophy or KTS-associated cortical thickening. Due to numerous vascular malformations invading the first to third metatarsal bones, further obscured undisplaced fractures could not be excluded. Follow-up CT, acquired after over 2 months (Fig. 3), showed no further fractures and progressive union of the fourth metatarsal bone.

\section{References}

1. Klippel M, Trénaunay P. Du Noevus Variqueux Osteo-Hypertrophique. Arch Gen Med (Paris). 1900;3:641-2.
2. Servelle M. Klippel and Trénaunay's syndrome. 768 operated cases. Ann Surg. 1985;201(3):365-73.

3. Timur AA, Driscoll DJ, Wang Q. Biomedicine and diseases: the Klippel-Trénaunay syndrome, vascular anomalies and vascular morphogenesis. Cell Mol Life Sci. 2005;62(13):1434-47.

4. Jacob AG, Driscoll DJ, Shaughnessy WJ, Stanson AW, Clay RP, Gloviczki P. Klippel-Trénaunay syndrome: spectrum and management. Mayo Clin Proc. 1998;73(1):28-36.

5. Baskerville PA, Ackroyd JS, Lea Thomas M, Browse NL. The Klippel-Trénaunay syndrome: clinical, radiological and haemodynamic features and management. Br J Surg. 1985;72(3):232-6.

6. Castriota-Scanderbeg A, Dallapiccola B. Abnormal skeletal phenotypes: from simple signs to complex diagnoses. Berlin Heidelberg New York: Springer; 2005. p. 732.

7. Kormano M, Lindgren I, Helander I. Radiological findings in skin diseases and related conditions. New York: Thieme; 1998:195.

8. Kihiczak GG, Meine JG, Schwartz RA, Janniger CK. KlippelTrénaunay syndrome: a multisystem disorder possibly resulting from a pathogenic gene for vascular and tissue overgrowth. Int $\mathrm{J}$ Dermatol. 2006;45(8):883-90. 